\title{
A case of complete colorectal anastomotic obstruction treated by fully covered metal stents of gradually increasing diameter
}

Benign colorectal postoperative stricture occurs in $5 \%-20 \%$ of cases of sigmoid resection or rectal anterior resection and often involves the distal extraperitoneal rectum. Anastomotic ischemia seems to play an important role. Surgical management with a "re-do" anastomosis was considered the standard treatment in previous years. Nowadays, balloon dilation is considered the gold standard for the treatment of anastomotic strictures, but the treatment often results in a restenosis [1]. A limited amount of data have been published in the literature about the use of fully covered metal stents (FCSEMSs) for the treatment of anastomotic refractory fibrotic strictures, but no data showing the effectiveness of gradually increasing the diameter of the FCSEMSs in the treatment of these patients has ever been published.

We describe the case of a 68-year-old man who had undergone Hartmann sigmoid resection and successive recanalization. After a few months, there was evidence of complete closure of the colorectal anastomosis with a lumen of just $2 \mathrm{~mm}$ in diameter ( $\vee$ Video 1 ). As a first step, the patient underwent placement of a $16 \times 30-\mathrm{mm}$ pseudocyst FCSEMS (Nagi; Taewoong Medical Co., Seoul, South Korea). After 50 days, this FCSEMS was changed to an enteral through-thescope 22-30×80-mm FCSEMS (Taewoong Medical Co.). About 2 months later, an over-the-wire 24-32 $\times 100-\mathrm{mm}$ FCSEMS (Taewoong Medical Co.) was substituted for the second stent. After 30 days, the third stent was removed and a lower gastrointestinal endoscopy showed complete resolution of the stricture ( $\downarrow$ Video 1 ). This treatment using FCSEMSs of gradually increasing diameter, in expert hands, is a safe and efficacious strategy for the treatment of the benign colorectal anastomosis.

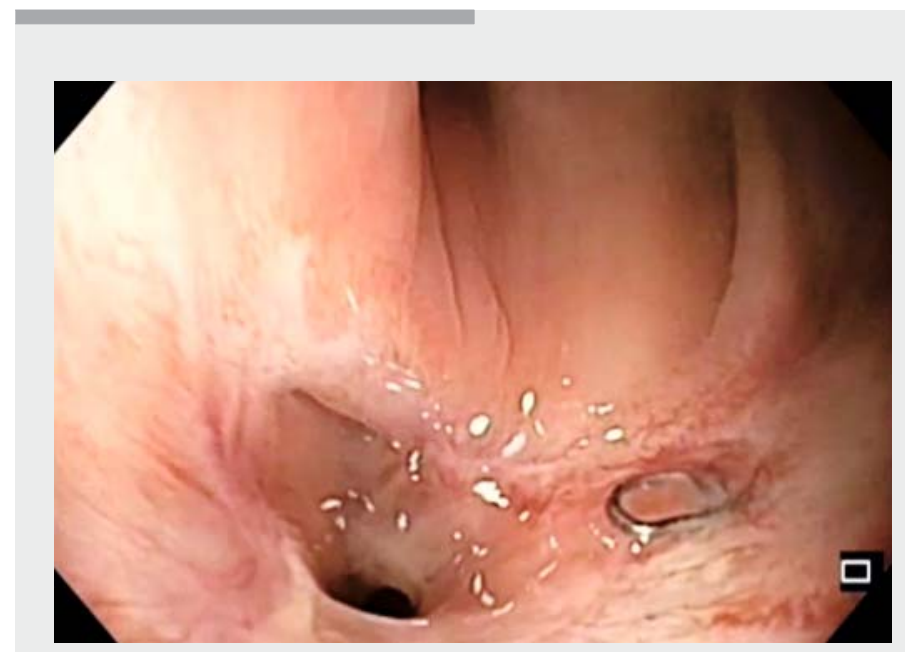

Video 1 Endoscopic appearance of the obstructed colorectal anastomosis with a residual lumen of only a few millimeters and the successful endoscopic technique of treating with three consecutive FCSEMSs of gradually increasing diameter.

Endoscopy_UCTN_Code_TTT_1AQ_2AF

\section{Competing interests}

The authors declare that they have no conflict of interest.

The authors

Benedetto Mangiavillano ${ }^{1,2}$, Francesco Auriemma ${ }^{1}$, Mario Bianchetti ${ }^{1}$, Francesca Scaltrini ${ }^{3}$, Andrea Porta ${ }^{4}$, Alessandro Repici ${ }^{2,5}$

1 Gastrointestinal Endoscopy Unit, Humanitas Mater Domini, Castellanza (VA), Italy

2 Humanitas University - Hunimed, Milan, Italy

3 Surgical Unit, Carate Brianza Hospital, Carate Brianza, Italy

4 Surgical Unit, Fatebenefratelli, Erba (CO), Italy

5 Digestive Endoscopy Unit, Istituto Clinico Humanitas Research Hospital, Milan, Italy

\section{Corresponding author}

Benedetto Mangiavillano, MD Gastrointestinal Endoscopy Unit, Humanitas

- Mater Domini, Via Gerenzano n. 2, 21053 - Castellanza (VA), Italy bennymangiavillano@gmail.com

Reference

[1] Adler DG. Colonic strictures: dilation and stents. Gastrointest Endosc Clin N Am 2015; 25: 359-371

Bibliography

DOI https://doi.org/10.1055/a-1144-2300

Published online: 17.4.2020

Endoscopy 2020; 52: E385

(c) Georg Thieme Verlag KG

Stuttgart · New York

ISSN 0013-726X 